\title{
Researchers tweet technical talk
}

\section{In the latest trend in scientific discourse, journal clubs and data disclosures move to Twitter.}

\section{BY EUGENIE SAMUEL REICH}

$\mathrm{R}$ obert Boyle would not have approved. The famously verbose seventeenthcentury natural philosopher and pioneer of the scientific method argued that technical communication demands detail, not brevity. But there is no room for Boylelike excess within the confines of the socialnetworking site Twitter, where users converse in 140-character posts, or 'tweets'. Researchers are now using the site's abbreviated messages to discuss papers in journal clubs and to share data in real time.

Scientists were among the early adopters when Twitter was launched five years ago, and many now use the site to tweet updates from conferences, promote links to papers, network and gossip. But using Twitter to engage in technical discussions with remote colleagues "is a novel thing", says Cornelius Puschmann, a linguist and information scientist at the University of Düsseldorf in Germany, who has tracked scientists' use of social media. Proponents say that Twitter enables fast-moving conversations, and allows users to post links pointing to more detail where required.

A medical-journal club started by Fiona Douglas, a medical student at the University of Cambridge, UK, and Natalie Silvey, a doctor at University Hospitals Coventry and Warwickshire in Coventry, UK, has held three weekly meetings since it began this month. A group for astronomers met for the first time last week.

In the inaugral session of the medical club on 5 June, around 60 participants discussed an influential paper on the treatment of acute sepsis and septic shock (E. Rivers et al. N. Engl. J. Med. 345, 1368-1377; 2001). Silvey says that the participants encompassed a wider range of expertise and career stages than would be seen at a conventional journal club, and that the technical quality of the discussion was high. Some participants used data in the paper to calculate the 'number needed to treat' (NNT), a measure of the effectiveness of an intervention based on the average number of patients who have to be treated for one to benefit (see 'Medical chatter').

The format confounded some potential participants. Ves Dimov, an allergy doctor at the University of Chicago in Illinois, found the conversation hard to follow. "Only people who

DISCUSSION DATA
Medical chatter
On 5 June, a medical-journal club had
its first meeting on Twitter. The chat
was brisk and technical, as this extract
shows. NNT measures a treatment's
effectiveness; \#TwitJC is the hashtag that
identifies posts as part of the club. The
full transcript is at go.nature.com/iuidmy.
tobyhillman RT @TWSY: NNT to save
one life? \#twitjc -9:04 PM
drgrumble @amcunningham Not if we
are still arguing about whether or not the
result is meaningful. \#TwitJC -9:04 PM
simonpeteryoung @drgrumble @
twitjournalclub ah but then the non-
sig results are left vulnerable \#TwitJC
-9:04 PM
aj0610 @anaestheticdoc @TWSY
About 6 \#twitjc -9:04 PM

can wrap their minds around this somewhat chaotic environment will find Twitter journal clubs useful," he says.

On 11 June, Mike Brown, an astronomer at the California Institute of Technology in Pasadena, pioneered another use of Twitter when he 'live-tweeted' plots of observations he was making of the transit of the dwarf planet Haumea by its moon, Namaka, from the William Herschel Telescope on La Palma in the Canary Islands, Spain (see go.nature.com/ me9trl). "There is an interest in getting discoveries out there quickly," he says.

Simon Schaffer, a historian of science at the University of Cambridge, says that Twitter is not as different from traditional scientific communication as it may seem. Journals began as letters between scientists, and were only later collated and published. "The idea of the person-to-person message is the essence of communication in the sciences," says Schaffer. And although Boyle's published reports were longwinded, he and other early scientists also kept notebooks in which they succinctly listed facts and observations that they had heard from others in coffee shops and elsewhere. "In a sense, Boyle was already tweeting," says Schaffer. 